Bousquet, J. 6, 13

Brambilla, G. 3

Dusser, D. 20

Duvauchelle, T. 13, 28

Fabbri, L.M. 1

Formoterol HFA group 20

Ganderton, D. 3

Guenolé, E. 13, 28

Houghton, C.M. 35
Huchon, G. 1, 6

Langley, S.J. 35

Leclerc, V. 6

Lefrançois, G. 6, 13, 20, 28

Lewis, D.A. 3

Meakin, B.J. 3

Molimard, M. 28

Singh, S.D. 35

Vicaut, E. 6, 13, 20, 28

\title{
Subject Index Vol. 72, Suppl. 1, 2005
}

Asthma 6, 13, 20, 28, 35

Bronchodilation 6, 13, 35

Bronchoprotection 35

Cardiac safety 28

Clinical equivalence 6,13

Cumulative doses 28

Dry powder inhaler $6,13,20,28,35$

Formoterol 6, 13, 20, 28, 35
Hydrofluoroalkane 3, 6, 13, 20, 28, 35

Lung function $6,13,20,35$

Modulite $^{\circledR}$ 3, 20, 28, 35

Non-inferiority 6, 20

Pressurised metered-dose inhaler 3, 6, 13, $20,28,35$

QTc interval 6, 13, 20,28

\section{KARGER}

(C) 2005 S. Karger AG, Basel

Fax + 41613061234 